\title{
Análise multidimensional de consórcios cenoura-alface sob diferentes combinações de densidades populacionais
}

\author{
Francisco Bezerra Neto(1), Eliane Gonçalves Gomes ${ }^{(2)}$, Glauber Henrique de Sousa Nunes ${ }^{(1)}$ \\ e Aurélio Paes Barros Júnior ${ }^{(1)}$
}

\begin{abstract}
(1)Universidade Federal Rural do Semi-Árido, Dep. de Fitotecnia, Caixa Postal 137, CEP 59625-900 Mossoró, RN. E-mail: bezerra@ufersa.edu.br, glauber@ufersa.edu.br, aureliojr02@yahoo.com.br (2)Embrapa Sede, Secretaria de Gestão Estratégica, Parque Estação Biológica (PqEB), Av. W3 Norte Final, CEP 70770-901 Brasília, DF. E-mail: eliane.gomes@embrapa.br
\end{abstract}

\begin{abstract}
Resumo - Este trabalho teve como objetivo avaliar o desempenho biológico de sistemas consorciados de cenoura e alface, sob diferentes combinações de densidades populacionais, com uso das análises bivariada de variância e envoltória de dados (DEA). O delineamento experimental usado foi o de blocos ao acaso completos, com cinco repetições, com os tratamentos arranjados em esquema fatorial $4 \mathrm{x} 4$. Os tratamentos resultaram da combinação de quatro populações de plantas de cenoura (40, 60, 80 e 100\% da população recomendada no cultivo solteiro PRCS) com quatro populações de plantas de alface (40, 60, 80 e 100\% da PRCS). As populações recomendadas para os cultivos solteiros da cenoura e alface foram 500 mil e 250 mil plantas por hectare, respectivamente. Tanto o método bivariado como o método de análise de envoltória de dados são bastante eficazes na discriminação dos melhores sistemas de cultivo consorciados, por meio dos rendimentos das culturas. Os resultados da eficiência produtiva, medidos por modelos DEA, permitem uma análise estatística simples do ensaio consorciado. A robustez do método de análise bivariada de variância assegura a validade dos resultados.
\end{abstract}

Termos para indexação: Daucus carota, Lactuca sativa, análise bivariada, análise envoltória de dados, experimentos consorciados.

\section{Multidimensional analysis of carrot-lettuce intercroppings under different combinations of population densities}

\begin{abstract}
The objective of this paper was to evaluate the biological performance of carrot and lettuce intercropping systems under different combinations of population densities, using the bivariate analysis of variance and data envelopment analysis (DEA). The experimental design was the randomized complete blocks, in a $4 \times 4$ factorial scheme (carrot densities: $40,60,80$ and $100 \%$ of the recommended sole crop density (RSCD); lettuce densities: 40, 60, 80 and 100\% of the RSCD), with five replications. The recommended population density for carrot in sole crop is 500 thousand plants per hectare and for lettuce in sole crop is 250 thousand plants per hectare. Both bivariate method of variance and data envelopment analysis are quite effective in discriminating the best intercropping systems as assessed through component crop yields. The results of the yield efficiency as assessed by DEA models allow a simple statistical analysis of the intercropping experiment. The robustness of the bivariate analysis of variance method assures the validity of the results.
\end{abstract}

Index terms: Daucus carota, Lactuca sativa, bivariate analysis, data envelopment analysis, intercropping experiments.

\section{Introdução}

O sistema de cultivo consorciado tem sido definido, genericamente, como o plantio de mais de uma cultura, simultaneamente, numa mesma área de terra, durante parte ou todo o período de desenvolvimento das culturas. Os resultados das produções advindas das culturas, nesse sistema de cultivo em uma mesma parcela, não são independentes, pois existe uma íntima relação entre elas que pode ser traduzida em correlação positiva ou negativa.

Há duas causas principais de interdependência das produções das duas culturas cultivadas na mesma parcela. Se a competição entre as duas culturas é intensa, então pode ser esperado que naquelas parcelas onde a cultura A tenha um desempenho excepcionalmente bom, a cultura B terá um desempenho excepcionalmente mau e vice-versa. Isto levaria a uma correlação negativa entre 
as duas produções das culturas, bastante afastada de qualquer padrão de variação conjunta causada pelos tratamentos aplicados. Não levar em conta esta correlação negativa em um método de análise conduziria a altos erros-padrão das médias, para cada cultura analisada separadamente e, como conseqüência, mascararia reais diferenças entre os tratamentos (Mead, 1990; Tageldin, 1998).

No entanto, pode ser que em parcelas aparentemente idênticas, as duas culturas respondam de maneira similar a pequenas diferenças entre parcelas e produzam uma correlação positiva.

A análise univariada de variância, sem considerar a relação entre as culturas, pode levar a erros-padrão altos para as médias dos tratamentos, e as comparações de tratamentos podem não mostrar as verdadeiras diferenças entre eles (Carvalho, 1996). Assim, é importante que a análise escolhida examine o relacionamento entre duas ou mais variáveis medidas nas duas culturas. A análise bivariada de variância examina os padrões de variação de ambas as culturas ao mesmo tempo e, assim, pode ser usada como um procedimento padrão para interpretação destes tipos de dados.

A principal vantagem da análise bivariada é que ela conduz a uma forma simples de apresentação gráfica das médias dos pares dos rendimentos das culturas, e permite a correlação entre aquelas produções. Ao invés de eixos perpendiculares, na apresentação das médias dos tratamentos para as duas produções, na análise bivariada usam-se eixos não ortogonais para as duas produções, a fim de se eliminar a tendência de mostrar uma correlação negativa ou positiva nos eixos perpendiculares.

Antes de se fazer a análise bivariada, deve-se testar as pressuposições da análise univariada de variância de cada variável estudada. Além dessas pressuposições, três outras devem ser testadas. A primeira é a de que haja similaridade nas matrizes de covariância das variáveis estudadas; a segunda é a de que os resíduos destas variáveis tenham distribuição normal bivariada, e a terceira é que a correlação entre essas variáveis não varie entre os níveis dos tratamentos testados (Lavorenti, 1998).

A metodologia para construir gráfico com eixos não perpendiculares foi primeiramente apresentada por Pearce \& Gilliver (1979). Posteriormente, foi detalhada por Dear \& Mead $(1983,1984)$. Esta metodologia deve facilitar a interpretação dos resultados de experimentos de consorciação. Vários modelos, com um ou dois fatores tratamento, foram ajustados por Lavorenti (1998), partindo-se a soma de quadrado de tratamentos, combinada em várias componentes, em uma análise bivariada usando-se a transformação ortogonal das respostas da variável original.

Uma maneira de se contornar o caráter multivariado dos dados de um experimento consorciado tem sido trabalhar com uma resposta unidimensional que agregue os resultados multidimensionais das culturas envolvidas. O propósito é facilitar a interpretação dos resultados do ensaio experimental e tornar menos complexa sua análise. O LER (Land Equivalent Ratio) é uma abordagem deste tipo, definido como a soma dos quocientes das produções obtidas sob consórcio pelas produções esperadas, solteiras, respectivas. Alternativamente, modelos de análise de envoltória de dados (Cooper et al., 2004; Bezerra Neto et al., 2007) foram propostos para gerar uma medida de eficiência (unidimensional) para cada parcela de experimentos consorciados. Modelos de análise envoltória de dados (DEA) calculam a eficiência relativa de unidades produtivas e usam problemas de programação linear, que otimizam cada observação individual de modo a estimar uma fronteira eficiente, linear por partes, composta das unidades que apresentam as melhores práticas dentro da amostra em avaliação. A eficiência relativa é definida como a razão da soma ponderada, das componentes do vetor de produção, pela soma ponderada das componentes do vetor de recursos usado no processo de produção. Os pesos usados nas ponderações das componentes de recursos e produtos são distintos e obtidos dos problemas de programação linear de DEA. A vantagem do DEA é agregar em uma medida única as múltiplas respostas do experimento.

Os modelos DEA têm dois principais postulados: na fronteira eficiente, os produtos são funções não decrescentes dos recursos; se é possível produzir de forma eficiente, também é possível produzir de forma não eficiente. Como pressuposto geral da DEA, as unidades em avaliação devem ser homogêneas. O tipo de modelo DEA usado é um pressuposto de cada modelagem individual.

As medidas univariadas geradas pelos modelos DEA, aqui chamadas de eficiências produtivas, podem ser analisadas com as técnicas padrão de análise de variância e covariância. No caso de experimentos 
com resposta unidimensional, a análise é equivalente à prática usual e facilita a interpretação de experimentos complexos pela redução da dimensão do vetor resposta.

Bezerra Neto et al. (2007) ao estudar a produtividade biológica em sistemas consorciados de cenoura e alface, avaliada através de indicadores agroeconômicos e métodos multicritério e DEA, observaram vantagens em todos os consórcios de cenoura e alface testados em termos agronômicos (produtividade e ambiente) e econômicos (rendimentos financeiros).

O presente trabalho teve por objetivo avaliar, por meio da análise bivariada de variância e da análise de envoltória de dados, a resposta dos rendimentos de cenoura e alface, em cultivos consorciados sob diferentes combinações de densidades populacionais de ambas as culturas.

\section{Material e Métodos}

O experimento foi realizado na horta do Departamento de Ciências Vegetais, da Universidade Federal Rural do Semi-Árido, de junho a setembro de 2003, em Argissolo Vermelho-Amarelo eutrófico. Amostras de solo coletadas foram processadas e analisadas no Laboratório de Química e Fertilidade de Solos da referida Universidade, cujos resultados foram: $\mathrm{pH}$ (água 1:2,5), 8,49; Ca, 7,12 $\mathrm{cmol}_{\mathrm{c}} \mathrm{dm}^{-3} ; \mathrm{Mg}, 4,48 \mathrm{cmol}_{\mathrm{c}} \mathrm{dm}^{-3}$; $\mathrm{K}, 1,64 \mathrm{cmol}_{\mathrm{c}} \mathrm{dm}^{-3} ; \mathrm{Na}, 0,24 \mathrm{cmol}_{\mathrm{c}} \mathrm{dm}^{-3} ; \mathrm{Al}$, $0,00 \mathrm{cmol}_{\mathrm{c}} \mathrm{dm}^{-3}$; e P, 382,7 $\mathrm{mg} \mathrm{dm}^{-3}$.

O delineamento experimental utilizado foi o de blocos ao acaso completos, com cinco repetições, com os tratamentos arranjados em esquema fatorial $4 \times 4$. Os tratamentos resultaram da combinação de quatro populações de plantas de cenoura (40, 60, 80 e 100\% da população recomendada no cultivo solteiro - PRCS), com quatro populações de plantas de alface $(40,60,80$ e $100 \%$ da PRCS). A alface foi transplantada para o sistema consorciado com a cenoura aos 11 e 75 dias do plantio da cenoura, na mesma população acima descrita (Oliveira et al., 2004). A população recomendada para o cultivo solteiro da cenoura, na região, foi de 500 mil plantas por hectare (Barros Júnior et al., 2005) e, no cultivo da alface, 250 mil plantas por hectare (Silva et al., 2000), sem levar em consideração os $30 \%$ de área de trânsito, composta de corredores e estradas. Para as características de produtividade das culturas, foram feitas as correções para $70 \%$ da área plantada.
Cada parcela no sistema consorciado foi constituída de quatro fileiras em faixa de cada cultura, ladeada por uma fileira guarda (ou bordadura). As parcelas tinham uma área total de 1,92 m², com uma área útil de 1,60 m². O espaçamento de plantio e o número de plantas na área útil variaram de acordo com cada nível populacional, em cada combinação entre as populações de alface e cenoura.

A cultivar de alface utilizada no experimento foi a Tainá, indicada para o mercado de consumo fresco em razão do excelente sabor. Caracteriza-se pela alta capacidade produtiva, boa formação de ombro e alta resistência ao pendoamento precoce. A cultivar de cenoura foi a Brasília, indicada para a Região Nordeste (Oliveira et al., 2004).

Nas parcelas cultivadas com cenoura, alface solteira e em consórcio, foram realizadas adubações com $80 \mathrm{t} \mathrm{ha}^{-1}$ de esterco de bovinos, com $40 \mathrm{~kg} \mathrm{ha}^{-1}$ de nitrogênio, na forma de uréia, $60 \mathrm{~kg} \mathrm{ha}^{-1}$ de $\mathrm{P}_{2} \mathrm{O}_{5}$, na forma de superfosfato simples, e $30 \mathrm{~kg} \mathrm{ha}^{-1} \mathrm{de}_{2} \mathrm{O}$, na forma de cloreto de potássio, de acordo com a análise realizada no solo.

Foram realizadas duas adubações nitrogenadas em cobertura, uma aos 25 dias após o plantio e a outra aos 45 dias após o plantio da cenoura com $40 \mathrm{~kg} \mathrm{ha}^{-1}$ de nitrogênio, em forma de uréia. Junto com a primeira adubação de cobertura nitrogenada, foi realizada uma adubação potássica de $30 \mathrm{~kg} \mathrm{ha}^{-1}$ de $\mathrm{K}_{2} \mathrm{O}$.

Efetuaram-se também adubações foliares com $30 \mathrm{~mL}$ da formulação $14 \%$ de $\mathrm{N}, 4 \%$ de $\mathrm{P}_{2} \mathrm{O}_{5}, 6 \%$ de $\mathrm{K}_{2} \mathrm{O}$, $0,8 \%$ de $\mathrm{S}, 1,5 \%$ de $\mathrm{Mg}, 2 \%$ de $\mathrm{Zn}, 1,5 \%$ de $\mathrm{Mn}, 0,1 \%$ de B e $0,05 \%$ de Mo diluídos em 20 L de água, aos 25 e 30 dias após a semeadura da alface.

A alface foi semeada em primeiro cultivo em 30 de maio, e no segundo cultivo em 8 de agosto de 2003, em copos descartáveis de $150 \mathrm{~mL}$, com substrato comercial de uma mistura de fibra de coco e composto orgânico na proporção de 1:2. Foram semeadas de três a cinco sementes por recipiente e, aos três dias após a germinação, efetuou-se o primeiro desbaste, tendo-se deixado duas plântulas por recipiente, e aos oito dias o segundo desbaste, tendose deixado apenas uma plântula por recipiente. As mudas foram produzidas sob sombreamento, em uma estufa coberta com plástico branco leitoso. As mudas de alface do primeiro cultivo foram transplantadas para as faixas adjacentes da cenoura, aos 24 dias após a semeadura, e as do segundo cultivo aos 18 dias após a semeadura, quando a cenoura 
encontrava-se com 11 e 75 dias da semeadura, respectivamente.

A cenoura foi semeada em 12 de junho de 2003. O desbaste foi realizado 25 dias após a semeadura, tendo-se deixado apenas uma planta por cova.

Antes da instalação do experimento em campo, foi realizada a solarização dos canteiros de plantio, durante 60 dias, cuja finalidade foi evitar ou reduzir a população de fitopatógenos do solo, que viesse a prejudicar a produtividade da cultura da cenoura. Durante a condução do experimento, foram efetuadas capinas manuais e irrigação pelo sistema de micro-aspersão.

A colheita da cenoura foi realizada em 8 de setembro de 2003, quando completou um ciclo de 88 dias após o plantio. A colheita da alface no primeiro cultivo foi realizada nos dias 21 e 22 de julho de 2003, quando a cultura da cenoura estava aos 39 dias do plantio e a alface aos 52 e 53 dias da semeadura. No segundo cultivo da alface, a colheita foi realizada nos dias 18 e 19 de setembro de 2003, aos 41 e 42 dias da semeadura.

As características avaliadas foram: na cenoura, o rendimento comercial de raízes (obtida da massa das raízes das plantas da parcela útil, livres de rachaduras, bifurcações, nematóides e danos mecânicos, e expressada em $t \mathrm{ha}^{-1}$ ), e na alface, o rendimento de folha (avaliado através da massa fresca da parte aérea de todas as plantas da parcela útil, expressada em $\mathrm{t} \mathrm{ha}^{-1}$ ).

Para calcular a eficiência produtiva de cada parcela, foi usado o modelo DEA, com retornos constantes à escala (Cooper et al., 2004). Esse modelo pode ser formulado na forma do problema de programação fracionária apresentado em (1), em que: $\mathrm{w}_{\mathrm{ik}}$ é o valor do recurso $\mathrm{i}(\mathrm{i}=1 \ldots \mathrm{s})$, para a parcela $\mathrm{k}$ $(\mathrm{k}=1 \ldots \mathrm{n}) ; \mathrm{x}_{\mathrm{jk}}$ é o valor do produto $\mathrm{j}(\mathrm{j}=1 \ldots \mathrm{r})$, para a parcela $\mathrm{k} ; \mathrm{v}_{\mathrm{i}}$ e $\mathrm{u}_{\mathrm{j}}$ são pesos atribuídos a recursos e produtos, respectivamente; $\mathrm{O}$ é a parcela em análise. Pela interpretação do modelo formulado em (1), busca-se encontrar o valor dos pesos atribuídos a recursos e produtos (incógnitas deste modelo), de modo que cada parcela $\mathrm{O}$ obtenha a máxima medida de eficiência possível $h_{O}$, dada pela razão da soma ponderada dos produtos pela soma ponderada dos recursos. Como condições restritivas, todas as parcelas não podem ter eficiência superior à unidade (ou 100\%), e os pesos atribuídos a todos os recursos e produtos devem ser positivos. Para se calcular as medidas de eficiência é necessário rodar um modelo DEA para cada parcela $\mathrm{k}$.
$\operatorname{Max} \mathrm{h}_{\mathrm{O}}=\left(\frac{\sum_{\mathrm{j}=1}^{\mathrm{r}} \mathrm{u}_{\mathrm{j}} \mathrm{x}_{\mathrm{jO}}}{\sum_{\mathrm{i}=1}^{\mathrm{s}} \mathrm{v}_{\mathrm{i}} \mathrm{w}_{\mathrm{iO}}}\right)$

sujeito a

$\frac{\sum_{j=1}^{r} u_{j} x_{j k}}{\sum_{i=1}^{s} v_{i} w_{i k}} \leq 1, \quad k=1 \ldots n$

$u_{j}, v_{i} \geq 0, \quad i=1 \ldots s, \quad j=1 \ldots r$

A resolução da formulação fracionária (1) apresenta um número infinito de soluções. Entretanto, as transformações propostas por Charnes \& Cooper (1962), para problemas de programação fracionária, permitem selecionar uma solução representativa, isto é, solução para o vetor $(\mathrm{u}, \mathrm{v})$, para o qual $\sum_{\mathrm{i}=1}^{\mathrm{s}} \mathrm{v}_{\mathrm{i}} \mathrm{w}_{\mathrm{i} O}=1$. Essa transformação resulta no problema de programação linear equivalente, apresentado em (2), no qual a mudança de variáveis $(u, v)$ para $(\mu, v)$ resulta da transformação de Charnes-Cooper. É sob a formulação (2) que os cálculos das medidas de eficiência DEA são usualmente conduzidos.

$\operatorname{Max} z=\sum_{j=1}^{r} \mu_{j} x_{j O}$

sujeito a

$\sum_{\mathrm{i}=1}^{\mathrm{s}} \mathrm{v}_{\mathrm{i}} \mathrm{w}_{\mathrm{iO}}=1$

$\sum_{\mathrm{j}=1}^{\mathrm{r}} \mu_{\mathrm{j}} \mathrm{x}_{\mathrm{jk}}-\sum_{\mathrm{i}=1}^{\mathrm{s}} v_{\mathrm{i}} \mathrm{w}_{\mathrm{ik}} \leq 0, \mathrm{k}=1 \ldots \mathrm{n}$

$\mu_{j}, v_{i} \geq 0, \quad i=1 \ldots s, \quad j=1 \ldots r$

Para o caso em estudo, as unidades de avaliação foram as parcelas, em um total de 80 (16 tratamentos fatorial $4 \times 4$ - com 5 repetições). Como produtos, usaramse o rendimento comercial de raízes da cenoura e o rendimento de folhas da alface. Para avaliar o desempenho de cada parcela, considerou-se que cada uma utiliza um único recurso com nível unitário (Lovell \& Pastor, 1999; Soares de Mello \& Gomes, 2004; Bezerra Neto et al., 2007), já que os produtos 
incorporam os possíveis recursos. Esta hipótese de recurso unitário é adequada a ensaios experimentais, pois permite às parcelas a mesma base de comparação.

No caso aqui em estudo, a pressuposição de homogeneidade das parcelas em avaliação foi aceita, já estas utilizam os mesmos recursos para produzir os mesmos produtos. Quanto ao pressuposto de retornos constantes de escala, este é um modelo válido, visto que para modelos com recurso unitário orientados a recursos, os resultados dos modelos com retornos constantes de escala são equivalente aos resultados dos modelos DEA com retornos variáveis de escala, conforme provado por Lovell \& Pastor (1999).

As pressuposições da análise univariada de variância das variáveis estudadas foram assim checadas: normalidade, verificada pelo teste W de Shapiro \& Wilk (Oliveira \& Corrêa-Ferreira, 1998); homogeneidade de variâncias, verificada pelo teste do $\chi^{2}$ de Bartlett (Oliveira \& Corrêa-Ferreira, 1998) e aditividade, verificada pelo teste $\mathrm{F}$ de Tukey (Oliveira \& CorrêaFerreira, 1998).

Para a análise bivariada de variância foram checadas as seguintes pressuposições: normalidade bivariada, verificada pelo método gráfico dos percentis do quiquadrado contra as distâncias de Mahalanobis ao quadrado (Lavorenti, 1998); igualdade das matrizes de covariância, verificada pela estatística M de Box (Pallant, 2001) e independência das variáveis dependentes, verificada pelo teste da esfericidade $\left(\chi^{2}\right)$ de Bartlett (Pallant, 2001).

Uma análise bivariada de variância para o delineamento de blocos ao acaso completos foi utilizada nos rendimentos avaliados na cenoura e na alface, conforme procedimento sugerido por Pearce \& Gilliver (1979). Este procedimento consiste em exibir os pares das médias dos tratamentos em um eixo não perpendicular, utilizando-se uma transformação ortogonal nos rendimentos observados das culturas. Esta transformação pode ser definida nos dados, conforme apresentado em (3) e (4).

$\mathrm{Y}_{\mathrm{lij}}=0,005 \mathrm{X}_{\mathrm{lij}}$

$\mathrm{Y}_{2 \mathrm{ij}}=\left(\mathrm{X}_{2 \mathrm{ij}}-\mathrm{V}_{12} \mathrm{X}_{1 \mathrm{ij}} / \mathrm{V}_{11}\right) / \sqrt{\mathrm{V}_{22}-\mathrm{V}_{12}^{2} / \mathrm{V}_{11}}$

em que: $\mathrm{Y}_{1 \mathrm{ij}}$ é o valor da variável 1 , transformada na i-ésima combinação de densidade populacional de cenoura e alface em consórcio; $\mathrm{Y}_{2 \mathrm{ij}}$ é o valor da variável 2, transformada na i-ésima combinação de densidade populacional de cenoura e alface em consórcio; $X_{1 \mathrm{ij}}$ é o rendimento da cenoura, na i-ésima combinação de densidade populacional de cenoura e alface em consórcio; $\mathrm{X}_{2 \mathrm{ij}}$ é o rendimento da alface, na i-ésima combinação de densidade populacional de cenoura e alface em consórcio; $\mathrm{V}_{11}$ é o quadrado médio do resíduo da análise de variância do rendimento de cenoura em consórcio, desconsiderando-se o rendimento da alface; $V_{22}$ é o quadrado médio do resíduo da análise de variância do rendimento de alface em consórcio, desconsiderando-se o rendimento da cenoura; $\mathrm{V}_{12}$ é o produto médio do resíduo da análise combinada dos rendimentos de cenoura e de alface, no experimento consorciado.

As variáveis $\mathrm{Y}_{1}$ e $\mathrm{Y}_{2}$ (não correlacionadas) têm variâncias residuais iguais a um e covariância nula. $\mathrm{O}$ ângulo entre os dois eixos dos dados originais (rendimentos das duas hortaliças - variáveis correlacionadas) é alcançado pela expressão: $\cos \theta=r_{x 1 \times 2}$ (coeficiente de correlação residual). Os efeitos dos fatores tratamentos foram avaliados pelos procedimentos de ajustamento de curvas usados por Lavorenti (1998). As estimativas dos erros-padrão dos parâmetros, nos modelos estimados, foram obtidas pelas 1.000 amostras obtidas pelo método de boostrap.

Uma análise univariada de variância, para o delineamento de blocos ao acaso completos, foi utilizada para avaliar o índice de eficiência produtiva (DEA), e os fatores tratamentos foram avaliados pelos procedimentos de ajustamento de superfície de resposta com o programa Table Curve Package (Systat Software Inc., 2002).

\section{Resultados e Discussão}

O coeficiente de correlação residual, entre os rendimentos das duas hortaliças, foi de $-0,12$, correspondente a um ângulo interno entre os eixos assimétricos de $96,72^{\circ}$. Este coeficiente negativo indica situação de pequena competição entre as culturas, decorrente ou do aumento na densidade da cenoura ou da alface estabelecida.

Os resultados dos testes das pressuposições da análise univariada de variância, para os rendimentos de cenoura (PDCEN) e de alface (PDALF), foram: homocedasticidade (PDCEN, $\chi^{2}=13,274, p=0,581$; PDALF, $\left.\chi^{2}=9,960, p=0,822\right)$; normalidade (PDCEN, $\mathrm{W}=0,981, \mathrm{p}=0,283$; PDALF, $\mathrm{W}=0,991$, $\mathrm{p}=0,839$ ); aditividade (PDCEN, $\mathrm{F}=0,390, \mathrm{p}=0,534$; PDALF, $F=0,480, p=0,493)$. Em nenhuma destas 
variáveis, as hipóteses foram rejeitadas, o que quer dizer que estas pressuposições foram atendidas. Para a análise bivariada, no teste da normalidade bivariada obteve-se praticamente uma linha reta a partir da origem, e o coeficiente de correlação entre as duas variáveis, no gráfico, foi de 0,9824 , significativo a $1 \%$ de probabilidade. Assim, pode-se assumir que os resíduos dos rendimentos da cenoura e alface realmente vêm de uma distribuição normal bivariada.

$\mathrm{O}$ valor da estatística M de Box, para o teste de igualdade das matrizes de covariância, foi de 59,693, baseado em 45 graus de liberdade, que é não significativo $(p=0,360)$. Isso indica que as matrizes de covariância dos rendimentos de cenoura e alface são similares entre os tratamentos. Esse tipo de teste é sensível à não-normalidade. Assim, ele também atesta a hipótese de que a normalidade dos dados é razoavelmente satisfatória.

$O$ resultado do teste da esfericidade de Bartlett foi de $\chi^{2}=24,393$ com $p=0,000$. Observa-se que é rejeitada a hipótese de que os rendimentos das culturas sejam independentes. Portanto, as pressuposições para a análise bivariada foram razoavelmente satisfeitas.
Não se observou efeito significativo da interação entre as densidades populacionais das culturas, nos vetores rendimentos de cenoura e de alface, pelo critério de Wilks, conforme apresentado na Tabela 1. No entanto, efeitos significativos das densidades populacionais de cenoura e de alface foram observados nos vetores rendimentos das duas hortaliças (Tabela 1), resultado esse semelhante aos obtidos pelo método univariado, usando-se o índice de eficiência produtiva (Tabela 2).

Uma resposta bivariada linear foi observada nos efeitos principais densidades de cenoura e de alface, em ambas as variáveis transformadas $\mathrm{Y}_{1}$ e $\mathrm{Y}_{2}$ (Figura 1). A cenoura aumentou os seus rendimentos médios de raízes comerciáveis em cerca de $55 \%$ e $9 \%$, em termos das variáveis $\mathrm{Y}_{1}$ e $\quad \mathrm{Y}_{2}$, respectivamente, independentemente da densidade populacional de alface (Tabela 1). Situação diferente foi observada na alface, com um aumento inexpressivo na variável $\mathrm{Y}_{1}$ e cerca de $30 \%$ na variável $\mathrm{Y}_{2}$, com aumento na densidade populacional da alface, independentemente da densidade populacional da cenoura (Tabela 1). Em termos de combinação de densidades populacionais, observou que os maiores

Tabela 1. Análise de variância multivariada da produtividade conjunta de alface e cenoura, parâmetros, estimativas, errospadrão e equações estimadas das variáveis transformadas das culturas, em função das densidades populacionais estudadas.

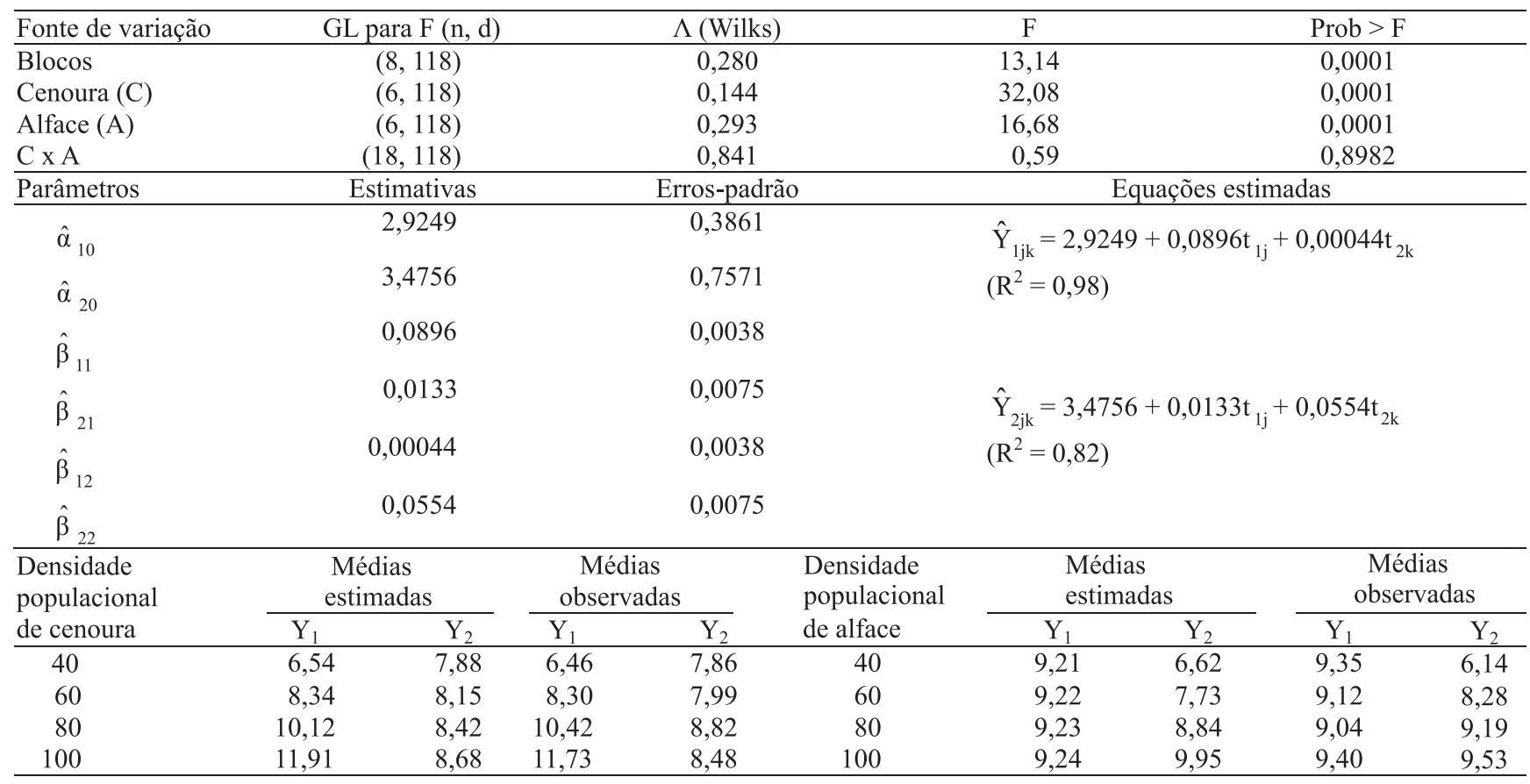


valores das variáveis $\mathrm{Y}_{1}$ e $\mathrm{Y}_{2}(11,93$ e 10,35) foram obtidos na associação da densidade de cenoura de $100 \%$ com a densidade de alface de $100 \%$ da PRCS (Figura 1).

Os resultados dos testes das pressuposições da homocedasticidade, normalidade e aditividade, na análise univariada de variância da variável eficiência produtiva analisada, foram: $\chi^{2}=1,478$ com $\mathrm{p}=0,964$; $\mathrm{W}=0,991 \operatorname{com} \mathrm{p}=0,842 ; \mathrm{F}=1,260 \operatorname{com} \mathrm{p}=0,266$ ). Nenhuma das hipóteses foi rejeitada, o que é necessário, segundo Lavorenti (1998), para validar os testes de significância e intervalos de confiança.

Tabela 2. Análise univariada de variância da eficiência produtiva e valores médios, em função das densidades populacionais de cenoura e alface testadas.

\begin{tabular}{lccc}
\hline Fonte de variação & GL & $\mathrm{F}$ & $\mathrm{P}$ \\
\hline Blocos & 4 & 12,45 & 0,0001 \\
Cenoura (C) & 3 & 32,30 & 0,0001 \\
Alface (A) & 3 & 5,01 & 0,0036 \\
C x A & 9 & 1,12 & 0,3634 \\
\hline Densidade & Eficiência & Densidade & Eficiência \\
populacional & produtiva & populacional $^{(1)}$ & produtiva \\
de cenoura $^{(1)}$ & (EFP) & de alface $^{(1)}$ & (EFP) \\
\hline 40 & 0,63 & 40 & 0,70 \\
60 & 0,71 & 60 & 0,75 \\
80 & 0,81 & 80 & 0,77 \\
100 & 0,83 & 100 & 0,80 \\
\hline CV $(\%)$ & 10,77 & & \\
\hline
\end{tabular}

(1)Porcentagens em relação à população recomendada no cultivo solteiro (PRCS).

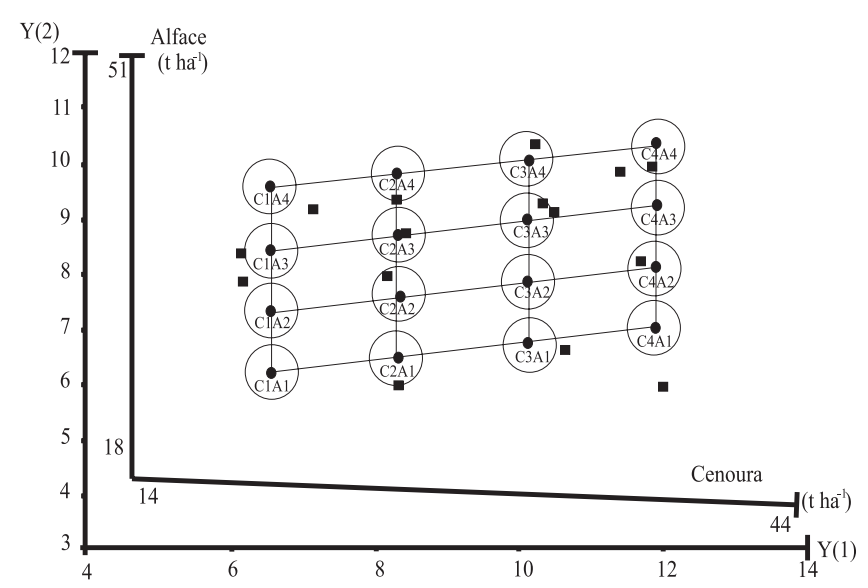

Figura 1. Variáveis não-correlacionadas das produtividades de cenoura e alface em função da combinação das densidades populacionais das duas hortaliças cultivadas em sistema consorciado.
Não houve interação significativa entre as densidades populacionais de cenoura e alface na variável eficiência produtiva. No entanto, efeitos significativos dos fatores principais foram observados nesta variável (Tabela 2), com um aumento linear no seu valor, à medida que as densidades populacionais das culturas aumentaram (Figura 2). Quando as densidades populacionais de cenoura e de alface aumentaram de 40 a 100\% da PRCS, a eficiência produtiva teve um incremento de aproximadamente 24 e 12,5\%, respectivamente (Tabela 2). Em termos de combinação das densidades populacionais de ambas as culturas, o maior valor observado na eficiência produtiva foi de aproximadamente 0,92 , na associação da densidade de cenoura de $100 \%$ com a densidade de alface de $100 \%$ da PRCS, o que correspondeu ao incremento de $37 \%$, em relação ao valor obtido na combinação de 40 e $40 \%$ da PRCS. Este resultado foi semelhante ao obtido pelo método bivariado. Em certos sistemas consorciados, seus melhores usos de recursos e, portanto, suas vantagens e eficiência de rendimento são maximizadas pelo aumento da pressão, nas densidades populacionais, a um nível maior ou semelhante aos das culturas componentes em cultivo solteiro. Provavelmente, foi isto o que aconteceu com o sistema obtido na densidade de cenoura de $100 \%$ com a densidade de alface de $100 \%$ da PRCS.

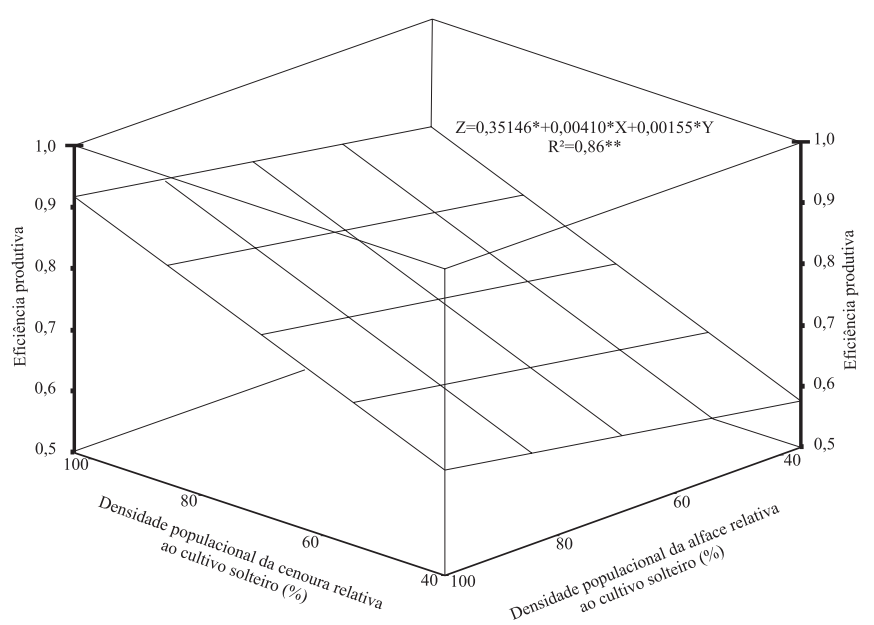

Figura 2. Eficiência produtiva de sistemas consorciados em função da combinação de densidade populacional de cenoura e de alface. 


\section{Conclusões}

1. Os métodos bivariado e de análise de envoltória de dados foram eficazes na discriminação dos sistemas de cultivo consorciados e na eleição dos melhores, por meio dos rendimentos das culturas envolvidas.

2. Os resultados da eficiência produtiva, medidos por modelos de análise de envoltória de dados, permitem uma análise estatística simples do ensaio consorciado.

3. O sistema consorciado de cenoura, na densidade de $100 \%$ da cultura solteira, com alface também na densidade de $100 \%$ da cultura solteira, é aquele a ser indicado ao produtor.

\section{Referências}

BARROS JÚNIOR, A.P.; BEZERRA NETO, F.; SILVA, E.O.; NEGREIROS, M.Z.; OLIVEIRA, E.Q.; SILVEIRA, L.M.; LIMA, J.S.S.; FREITAS, K.K.C. Qualidade de raízes de cenoura em sistemas consorciados com alface sob diferentes densidades populacionais. Horticultura Brasileira, v.23, p.290-293, 2005.

BEZERRA NETO, F.; GOMES, E.G.; OLIVEIRA, A.M. Produtividade biológica em sistemas consorciados de cenoura e alface avaliada através de indicadores agroeconômicos e métodos multicritério. Horticultura Brasileira, v.25, p.193-198, 2007.

CARVALHO, J.R.P. de. Consorciação de culturas: revisão e métodos de análise. In: SILVA, E.C. da. Métodos quantitativos e qualidade na Embrapa. Brasília: Embrapa-SPI, 1996. p.43-59.

CHARNES, A.; COOPER, W.W.; Programming with linear fractional functionals. Naval Research Logistics Quartely, v.9, p.181-185, 1962.

COOPER, W.W.; SEIFORD, L.M.; ZHU, J. Handbook on data envelopment analysis. Boston: Kluwer Academic Publishers, 2004. $608 \mathrm{p}$.

DEAR, K.B.G.; MEAD, R. Testing assumptions and other topics in bivariate analysis: statistics in intercropping. England: Department of Applied Statistics; Reading University, 1984. (Technical Report n.2)

DEAR, K.B.G.; MEAD, R. The use of bivariate analysis techniques for the presentation, analysis and interpretation of data: statistics in intercropping. England: Department of Applied Statistics; Reading University, 1983. (Technical Report n.1)

LAVORENTI, N.A. Fitting models in a bivariate analysis of intercropping. 1998. 310p. Thesis (Ph.D.) - University of Reading, Inglaterra.

LOVELL, C.A.K.; PASTOR, J.T. Radial DEA models without inputs or without outputs. European Journal of Operational Research, v.118, p.46-51, 1999.

MEAD, R. Statistical analysis of intercropping experiments designed to address basic research issues. In: WADDINGTON, S.R.; PALMER, A.F.E.; EDJE, O.T. (Ed.). Research methods for cereal/legume intercropping: proceedings of a workshop on research methods for cereal/legume intercropping in Eastern and Southern Africa, 1989, Malawi. Malawi: Winrock Pubns Sales, 1990. p.131-138.

OLIVEIRA, E.Q.; BEZERRA NETO, F.; NEGREIROS, M.Z.; BARROS JÚNIOR, A.P. Desempenho agroeconômico do bicultivo de alface em sistema solteiro e consorciado com cenoura. Horticultura Brasileira, v.22, p.712-717, 2004.

OLIVEIRA, M.C.N.; CORRÊA-FERREIRA, B.S. Diagnóstico exploratório na análise de dados entomológicos: efeito do diflubenzurom no consumo alimentar de Anticarsia gemmatalis (Hübner). Anais da Sociedade Entomológica do Brasil, v.27, p.627-637, 1998.

PALLANT, J. SPSS survival manual. Buckingham and Philadelphia: Open University Press, 2001. 286p.

PEARCE, S.C.; GILLIVER, B. Graphical assessment of intercropping methods. Journal of Agricultural Science, v.93, p.51-58, 1979.

SILVA, V.F. da; BEZERRA NETO, F.; NEGREIROS, M.Z.; PEDROSA, J.F. Comportamento de cultivares de alface em diferentes espaçamentos sob temperatura e luminosidade elevadas. Horticultura Brasileira, v.18, p.183-187, 2000.

SOARES DE MELLO, J.C.C.B.; GOMES, E.G. Eficiências aeroportuárias: uma abordagem comparativa com análise envoltória de dados. Revista de Economia e Administração, v.3, p.15-23, 2004.

SYSTAT SOFTWARE INC. Table curve 2D and 3D. San Jose: MMIV Systat Software Inc., 2002.

TAGELDIN, J.H. Bivariate analysis of variance of yield data from intercropping experiments. Journal of Agricultural Sciences, v.23-7, p.2981-2990, 1998.

Recebido em 6 de agosto de 2007 e aprovado em 30 de outubro de 2007 